\title{
Curriculum beyond the classroom: Exploring the use of Facebook as a learning platform
}

\author{
Khanal, Peshal $₫$ \\ Tribhuvan University, Nepal (peshal.khanal@cded.tu.edu.np) \\ https://orcid.org/0000-0003-2937-4906 \\ Bhattarai, Devi Prasad \\ Tribhuvan University, Nepal (devi.bhattarai@cded.tu.edu.np)
}

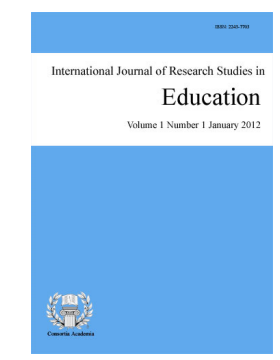

ISSN: $2243-7703$ Online ISSN: 2243-7711

OPEN ACCESS

\section{Abstract}

This paper explores the effectiveness of a Facebook intervention in students' learning through an action research project. This project aimed to provide students with increased and diversified opportunities for interaction, collaboration and learning. To this goal, a Facebook group was created among the students studying at the M.Ed. level specializing in Curriculum and Evaluation. Focusing on the learning contents of the Qualitative Research Methodology course, interventions were prepared and introduced regularly on this virtual platform. During the intervention, the instructors observed and analyzed the students' participation and learning on the Facebook group regularly. After completion of the interventions, a Focus Group Discussion (FGD) was conducted among the students to explore their experiences on using the Facebook group for their academic purpose. The Facebook group is found to be a platform to enrich and consolidate the learning received from face-to-face learning. Besides, this platform provides the students with the opportunity for interaction with colleagues within and beyond their classrooms. This group is also found to be an informal platform to bring teachers and students closer to each other which enhances opportunities for learning and collaboration. Overall, being flexible, informal and interactive, the Facebook group is effective for engaged learning.

Keywords: Facebook; Facebook group; internet; participation; learning; Nepal 


\section{Curriculum beyond the classroom: Exploring the use of Facebook as a learning platform}

\section{Introduction}

The use of Facebook, Messenger, Twitter, Skype, Google + and other social networking sites by students and teachers for creating learning opportunities has been a growing concern in higher education. A body of knowledge (e.g. Roblyer, 2010; Rana, 2013; Al-Dheleai \& Tasir, 2017; Wessels \& Diale, 2017) suggests that a large number of students and teachers have been using such social networking sites as an informal platform for learning. As a result, educational institutions allow such digital sites as supplementary tools for teaching and learning, and the demand and use of social media for educational purposes has been increasing ever than before.

As a social networking platform, Facebook has been a highly-used online tool in all sectors including teaching and learning (Bahati, 2015; Mayende et al., 2014; Wessels \& Diale, 2017). According to the recent information available on statista.com, Facebook is recently the largest networking site having more than 2.7 billion active users globally. As reported by Dulal (2014), around 1.93 percent of Nepali people have been using Facebook that has placed Nepal at 70th position in the world of Facebook users. Although the majority of students and teachers have poor access to Wi-Fi Internet services in rural educational institutions in Nepal (Acharya, 2016); the android version of Facebook is commonly used by teachers and students with Internet data pack of Nepal telecom and Ncell - the two giant telecommunication services in Nepal. As discussed by Joshi (2020), Facebook and social media have taken off big time in Nepal, as of October 2015, the number of Facebook users in Nepal was over five million (50 Lakhs) and this number was more than doubled (12 million) by 2020 . Among the users, $40 \%$ are female and $60 \%$ are male.

Considering the growth of Internet sites, it is imperative to use Facebook as a learning platform in a flexible way by both teachers and students, as there is a possibility that most of the higher education students have their Facebook account. Using this platform in teaching and learning may have several benefits, and as Ng'ambi (2011) values, the main goal is to facilitate students to interact and share informally (cited in Mayende et al., 2014). Students in the face-to-face classroom often seem to be shy and less interactive, who are less willing to take part in the discussion and interaction and hesitant to speak to the teachers about the problems they are facing. Despite the teachers' various efforts and strategies employed in teaching, classroom discussions and interactions are not meaningful and productive at the level of expectation for the shy and less active students in particular. The use of virtual sites for interaction and learning could help students who are less interactive and shy in face-to-face situations.

There are some shreds of evidence that students use the internet for other purposes than educational purposes. A case study of Nepalese high schools suggests that only a small proportion of Nepali students use the internet for educational purposes (Acharya, 2016). A significant number of teachers, students, and guardians view the internet as a medium of entertainment, not an educational resource. This suggests that there is a need for making teachers and students aware of the possibility of using the internet for learning purposes. In addition, there is a need for helping students avoid the addiction to Facebook and divert them towards using it for learning. Jha et al. (2016) argue that with limited academic benefits, excessive use of Facebook may increase the risk of Facebook addictive behavior, resulting in less time spent on academic activities.

While there is a growing trend of using Facebook for educational purposes, there is little evidence about the use of Facebook by students and teachers in Nepali educational institutions. Further, it is still unclear whether teachers and students are convinced that social networking could enhance learning. Most of the new generation teachers and students are active-user of Facebook, but it is unclear the extent to which they use this platform for teaching and learning when they are good users of social networking sites. 
In the above context, this study assesses the effectiveness of Facebook intervention for providing students with increased opportunities for learning in the classroom. In specific, this study seeks to answer the following questions:

$>\quad$ How do students use a Facebook group for enhancing their learning beyond the face-to-face mode of classroom practices?

$>\quad$ To what extent does this virtual forum provide them with opportunities for meaningful interaction and discussion?

$>$ How do students experience the use of the Facebook group for learning?

\section{Methods}

We designed an action research study for undertaking this research. At the initial stage of the study, pre-intervention quizzes, open questionnaires, and discussion threads were used online to solicit information about students' learning and preferences. Then a Facebook group as a forum for learning was created; the name of this group was, Curriculum Evaluation (C\&E06) (see Figure 1).

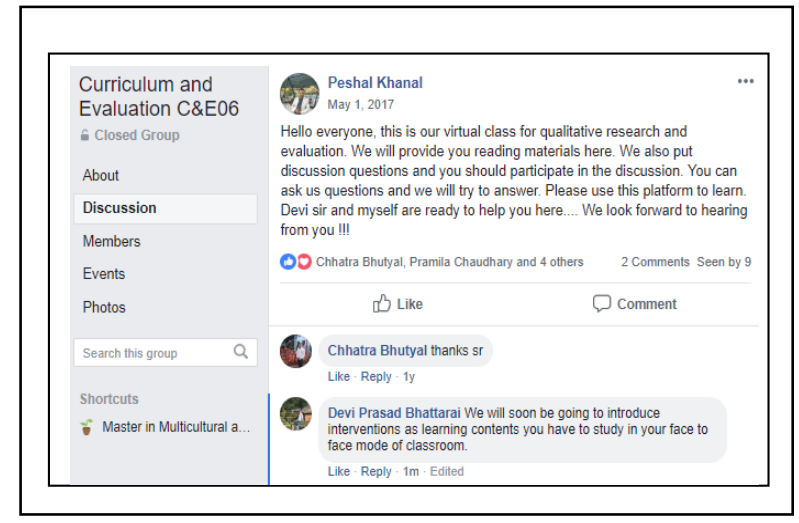

Figure 1. A snapshot of the Facebook group.

We posted the learning contents, questions and quizzes from the Qualitative Research Methodology course of M.Ed. Curriculum and Evaluation. And, we informed students to respond to such postings to make them engaged in virtual learning. As the students responded by answering and commenting on the posting, we gradually added other content, quizzes, and questions.

The target group of this study was the fourth-semester students specializing in Curriculum and Evaluation at M.Ed. level. As a result, six students (four girls and two boys) studying in the fourth semester from the Department of Curriculum and Evaluation were primary participants of this study. After introducing the intervention, this Facebook group was extended as the Facebook friends of those six students also got access to the group and joined the group's conversations. Besides students, two teachers responsible for teaching the Qualitative Research Methodology course were members of this Facebook group. We generated data based on the following cycle of action research:

Figure 2. Action research cycle.

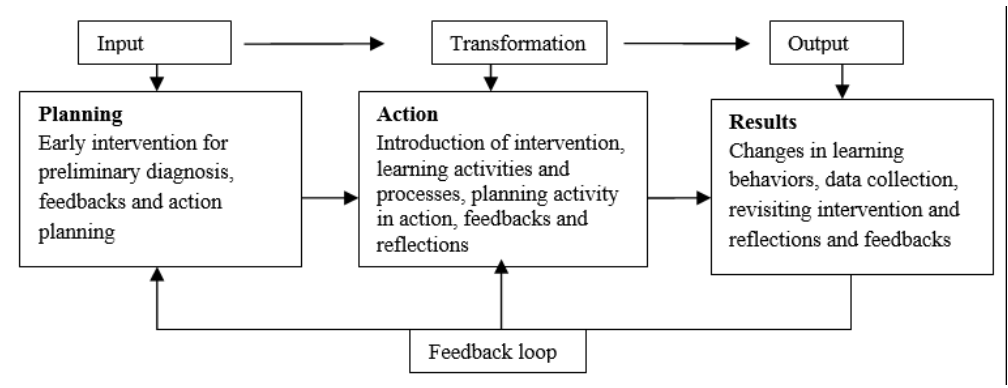




\subsection{Input as a planning phase}

Initially, a need-analysis question based on the learning content was posted which created a thread for discussion and interaction. This stage provided inputs to the students in order to explore their preliminary concerns, issues and feedback for further action. Providing inputs in the discussion thread, we aimed to explore students' problems, needs, and concerns, if any, while using the Facebook group for academic benefits.

\subsection{Transformation as an action phase}

We started this phase by putting the contents, short questions, quizzes, and open questionnaires related to the learning materials on the Facebook group. This phase was an implementing phase in which we introduced the interventions through posting on the Facebook group and observed the students' responses. In addition, we provided our feedback and reflections on their comments or answers. Our aim here was to assess how students engage in learning by participating through the Facebook group as well as to look at the ways they understand and learn the contents. We encouraged students for their enhanced responses, interactions and discussions on the Facebook group by providing them with our reflections and feedbacks.

\subsection{Results as an output phase}

We gathered data and information from the Facebook group, looking at the responses, comments and interactions. We observed the changes in students' learning behaviors and their participation in the Facebook group. We also assessed how effectively and efficiently the students commented, reflected and posted their ideas on the Facebook group. To achieve rich data, we also provided feedback to the students and reviewed our interventions. This way, we continually followed the cycle until the expected data were achieved.

The data received from the Facebook group were assessed and corroborated for their accuracy and validity by carrying out a post-intervention FGD with the same participants. We facilitated students to express their views, experiences, feelings, emotions, motives, difficulties and satisfactions regarding the use of the Facebook group for learning. Employing a thematic analysis, the data obtained from the series of interventions were grouped and coded. Basic themes were developed by grouping similar codes. And, gradually, organized and global themes were generated by comparing and merging the basic themes that provide similar meanings.

\section{Result and Discussion}

\subsection{Students' ways of using the Facebook group}

In this section, we discuss the findings related to the ways students use the Facebook group for their learning. Two major themes were derived: Facebook group as a platform for learning, and inter- and intra-group communication and interaction.

Facebook as a platform of learning - The Facebook group was found to be an informal platform for informing, sharing, interacting, and reflecting on subject-related knowledge and understanding. Through this virtual platform, students presented their ideas, made comments on the uploaded materials and posted their reflections and concerns. One of the participants shared that they participated in the Facebook discussion without any hesitation and fear, which she could not do in the face-to-face classroom. Students shared in the FGD that they felt very comfortable and easy to write questions and post their ideas on the Facebook group. They always felt encouraged to contact and talk to colleagues and teachers alike. A participant shared how she found the Facebook group as a platform for learning:

This Facebook group provided us with an opportunity for informal communication between students and teachers. This platform helped us to get access to the learning materials and

36 Consortia Academia Publishing (A partner of Network of Professional Researchers and Educators) 
increased opportunities for interactions and discussions on various topics that are not clear in the face-to-face classroom. In the absence of the instructor, we invited anyone for answering our questions, and in this way, we extended the communication beyond our group.

The discussion and interaction in the Facebook group were found influential, which were possible even in the absence of teachers. The sharing of ideas and concerns, and responding to the learning materials helped students understand the learning content from diverse perspectives. In a recent study, Al-Dheleai and Tasir (2017) also concluded that the students were willing to share their learning experience through interaction in such a virtual group and looking for support from others who can help them to understand the contents. In our interactions with students in FGD, they argued that the contents discussed in the face-to-face classroom were clarified and updated through wider conversations in the Facebook group. Students also called other teachers and someone interested in the field to join the group for the discussion on some specific contents. Regarding other benefits of the Facebook group, a student in the FGD shared:

If a Facebook group is introduced as a formal or informal learning platform, it offers two kinds of advantages: we can ask any questions any time and get responses from several colleagues and teachers which help to make every content clear, second, we have a strong social network that could help us for any educational needs in the future.

This statement suggests that the Facebook group not only works as a platform for enhancing the learning that is insufficient in the face-to-face classroom but also helps students strengthen their social capital which helps them grow professionally in the field. The use of the Facebook group by students suggests that they have used it as a supporting tool for gaining knowledge on the contents that they could not understand in the face-to-face classes. This is consistent with Al-Dheleai and Tasir's (2017) findings that:

Facebook mediated learning through questioning that made the students look for more information. Students also felt that Facebook was vital for students who did not attend face-to-face sessions. Students felt that Facebook enabled them to receive frequent updates about the course.

This suggests that the Facebook group helps students cover the lessons that they missed in the regular classroom and supplements the learning that students receive in the face-to-face classroom. Overall, students found the Facebook group as a platform for consolidating their learning through discussion and dialogue among colleagues and teachers.

Inter- and intra-group communication and interaction - As a virtual platform, the Facebook group provided a means for interconnectedness among the colleagues in sharing and discussing the difficulties and concerns as facilitated them for continued communication and interactions among each other. In the FGD, a participant revealed

The Facebook group provided a learning environment for interaction, sharing and discussing contents or issues, which is very encouraging. Such a learning environment supports us to extend our communication and connection beyond our assigned group for learning.

The group interacted primarily within the assigned group (Curriculum Evaluation-C\&E06) as an intra-group discussion and sharing. In addition, the assigned group extended to other students or groups as an inter-group as there was a possibility to include other students in the group as additional members - friend-of-friend. This extended students' conversations and dialogue beyond the usual assigned Facebook group, which has promoted an extended discourse for the greater learning community. In a similar context, Meishar-Tal et al. (2012) explored in their study that the students' perceived importance of the Facebook group as a learning space in evoking mutual support and social consolidation supports the collaborative learning process. We noticed that students collaborate with colleagues from the same and other departments in order to solve several problems. In 
doing so, the boundary of learning via Facebook group was not limited to only the assigned Facebook group but also went beyond joining all who are in the larger network of the Facebook of the primary members. Discussing this opportunity, a participant remark:

Many of our friends desired to join the Facebook group in order to share and discuss the subject-matter for greater learning, and I allowed them with limited access to commenting on my posting because of its formal nature belonged to the "Curriculum and Evaluation Department. Many of my colleagues joined in that way and contributed to our discussion.

An example of this extended group is shown in Figure 2. With such extended members, the Facebook group is considered as a forum for extending students' interaction and discussion for content learning even when the support of teachers is limited. Al-Dheleai and Tasir's (2017) highlighted the students learned through such forums in their own initiative without the presence of the instructors and got engaged in course-related content.

Figure 2. An example of extended members of the Facebook group.

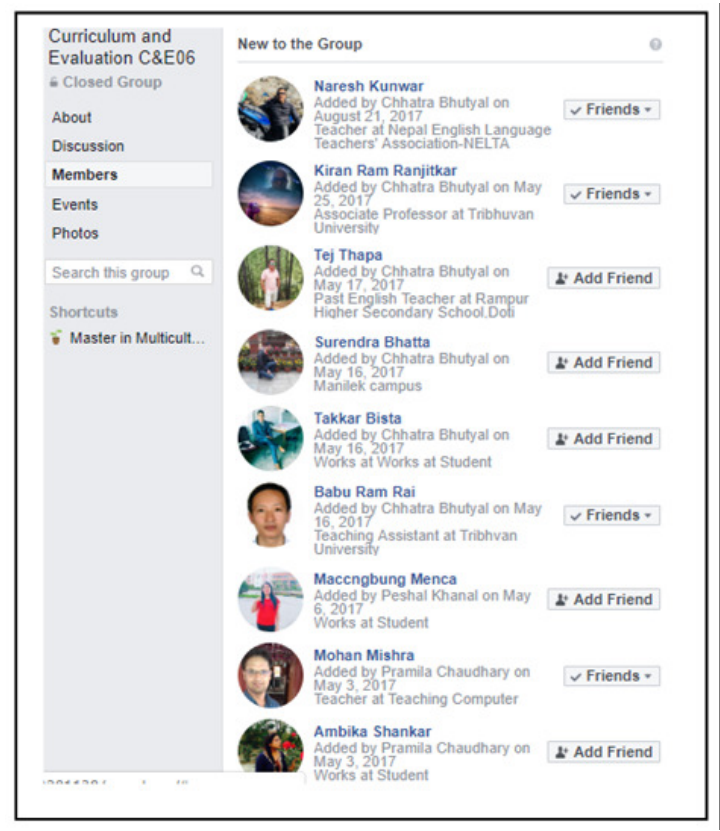

Our experiences suggest that the importance of instructors' regular presence on Facebook groups is important to facilitate students' learning and providing answers to some of the unresolved queries and concerns. In addition, the instructors' regular presence is effective to guide the students' activities in such a way that students are brought to the main track of the intended learning if they were derailed from the original discussion. This suggested that the Facebook group can be a pedagogical tool for creating a virtual learning environment where teachers and students promote engagement and discussion for learning. In addition, learning is effective if students and teachers work together as colleagues, rather than being distanced with traditional identities and roles of students and teachers.

\subsection{Nature of participation and interaction in the Facebook group}

The participation of students in the Facebook group for learning was found unique and wonderful. The discussion and interaction in the group revealed that students who were passive, introvert and shy in the face-to-face environment were found active in the Facebook group. In the FGD, a participant reveal:

I am always worried and feel shy in the face-to-face classroom to ask questions as well as to share my experiences with teachers and colleagues, but on Facebook, I do not worry much about what others would feel about me; ... I feel energetic while I participate in the Facebook group for discussion and interaction. 
It seems difficult for teachers to make all students participate in learning activities particularly in the face-to-face classroom. In such a situation, students who are shy and introvert in the face-to-face mode will have the opportunity for interactions and discussions on the Facebook group. Meishar-Tal et al. (2012) also shared that students feel comfortable taking part in the discussion on the Facebook group than in the regular classrooms. Reflecting upon the opportunities the students got on the Facebook group, we derive the following typical characteristics that explain the nature of students' participation in the Facebook group.

Flexibility: Facebook group offers a fair degree of flexibility to participate students in the discussion. With its flexibility, such a virtual group allows students to take part in learning activities at any time they feel comfortable. This helps students balance their time between work and study. A participant in the FGD revealed, "The Facebook group helps learn and interact with peers and teachers, irrespective of where I am and what I am doing. I can check the contents and provide my response in my free time". The flexibility that such virtual groups offer has two dimensions - spatial and temporal. With spatial flexibility, students staying anywhere can partake in the discussion, and with temporal flexibility, students can participate any time they feel comfortable. Al-Dheleai and Tasir's (2017) findings also suggest that learning from such a virtual forum allows students to join the learning activities regardless of the time they are available as well as of the place they belong to. Flexibility, thus, makes it possible to make learning participatory and inclusive.

Informal: The nature of students' participation in the Facebook group is informal, as it is not bound by any rigid rules and formalities (Figure 3). In addition, there is no artificial hierarchy between teachers and students. A participant viewed, "In a face to face classroom, there is always an artificial gap between teachers and students because of the formal and hierarchical role of the teacher. This creates a barrier to promoting healthy and natural conversations". In this context, the informal forum such as a Facebook group removes such barriers and provides equal grounds for students and teachers to initiate and sustain dialogue and discussions.

Figure 3. An example of informal conversation in the Facebook group.

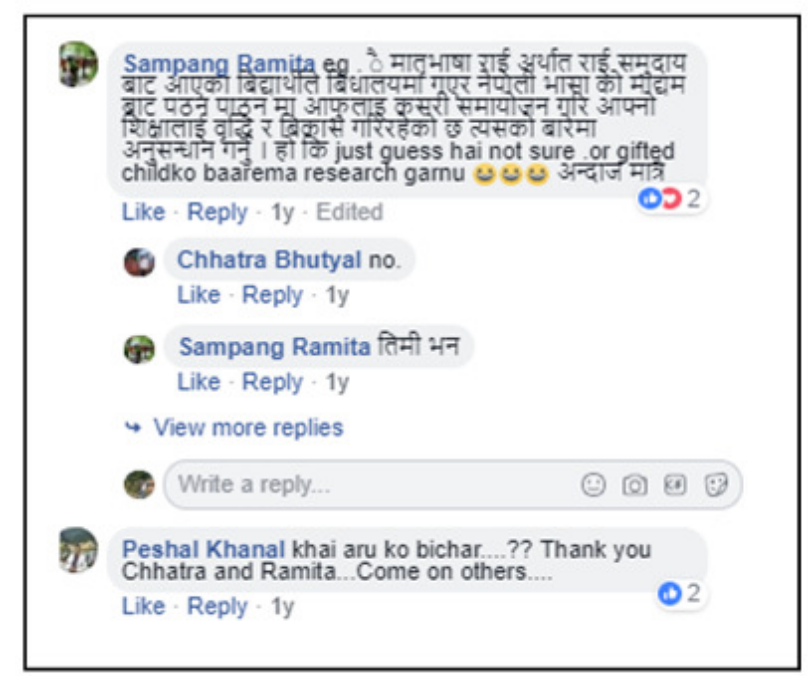

While the face-to-face mode of teaching and learning has its structural barrier to foster and continuous and meaningful conversations between teachers and students, the Facebook group creates an opportunity to express views and opinions in a very open and informal way, removing any artificial and hierarchical barrier between students and teachers. Dunn (2013) also argues that Facebook is a motivational tool that enhances collaboration and sharing between students and students, and students and teachers. This minimizes any artificial gap between them and removes the barrier to self-expression and contribution. The more informal nature of such a virtual forum creates an opportunity for a better learning opportunity for the weak and shy students in particular and thereby contributes to the wider participation of students in the learning activities.

Engaged: Facebook group provides a space for students as engaged learners through open and lively interaction and sharing with their colleagues and instructors. In the face to face mode, there is little chance for all students to engage in learning activities because of the time limitation. There are also problems such as poor 
learning environment, improper teachers' regular support, and insufficient teacher's time and materials which lessen the opportunity for all students to engage actively in the learning process. A participant shared,

I am always curious to learn in the face to face classroom, but the large class, inadequate time and limited teachers' support always discouraged me to ask questions and take part in the voluntary discussion. But now I can do this through the Facebook group.

This indicates the Facebook group provides opportunities for students to participate in learning in multiple ways - asking questions, responding to the post, engage in discussion, and others. Students having the enthusiasm to promote learning in face-to-face mode could meet their unfulfilled desires on the Facebook group by actively engaging themselves in the learning. Mayende et al. (2014) explored that both face-to-face and Facebook are vital and can complement each other. Not only students but teachers can also optimize the use of the Facebook group to explore the students' difficulties and problems and seek for engaging himself/herself in selecting and providing wider learning activities to the students.

Interactive: Facebook group creates an environment for several students with different abilities to share, discuss, and interact with the contents taught in their regular classroom. By putting comments and counter-comments on the posted materials as well as by participating in the group chat, the Facebook group promotes a healthy interaction and dialogue not only among students but also with the teachers. A participant asserted, "The Facebook group provided us an opportunity to share and interact with peers with different experiences. Our interaction was ongoing until each member of the group understood the matter. This reflects that knowledge is generated through interaction among peers with varied experiences and this interaction builds synergy among students as dynamic learners. This is consistent with findings discussed by Mayende et al. (2014) that face-to-face learning and distance learning was well mediated by the Facebook group as a tool, which increases the interaction among the learners. The nature of such a virtual group is always interactive in the sense that it promotes meaningful conversations among students and teachers until the point of saturation.

\subsection{Students'perception of the Facebook group}

The perception of students towards using the Facebook group is vivid and diverse. While there is agreement on the benefits of the Facebook group among students, students shared both rewarding experiences as well as the difficulties and pain in participating in this group. The following section elaborates on these findings.

Pleasure and satisfaction - Students shared their pleasure and satisfaction while learning and interacting with instructors and peers through the use of the Facebook group. They felt satisfied by getting the wider learning opportunity through the Facebook group that provided them with a space to interact with instructors and peers. In FGD, a participant revealed,

I am happy! This Facebook group made us able to keep in touch with teachers and classmates; and it worked as a tool for extending the connection to friend's friends for greater learning. I learned a lot by participating in this group.

This suggests that if interaction and sharing become pleasing and satisfying, the relation between instructor and students will be more productive for learning. Another participant comments, "I was a passive learner in the face-to-face classroom, but the Facebook group inspired me to become expressive. What I enjoyed most is that it I could speak out and I stood equal to others."

The students who were hesitant during the regular face-to-face class expressed a greater degree of satisfaction engaging in the virtual learning platform -commenting on the contents, posting their concerns or issues, or chatting with colleagues on the several issues of learning. This reveals that the Facebook group has become a motivating tool for students for learning, who are particularly hesitant to participate in learning activities in face-to-face classrooms. Meishar-Tal et al. (2012) revealed that the Facebook group encourages 
students to express themselves as a self-help tool, and removes barriers for participation in learning activities. While it is always difficult for teachers to assess students and provide grades, such virtual sites also become useful for providing quizzes and allow students to self-assess on the given contents based on the set criteria. And, in our works, students are also found happy to do quizzes and share their grades among friends (Figure 4). With all these possibilities, such an informal learning forum is reported better than formal classrooms. A participant revealed, "To me, the face-to-face classroom is always boring because they are formally structured around a certain technical content with a dominating role of the teacher; but learning through Facebook is both entertaining and effective". This indicates that students prefer informal learning forums with limited rules, structure and boundaries for learning. Sharing the benefits of the Facebook group, another participant elaborated, "Because of my busy schedule, it was difficult to share and discuss the subject-matters with friends and classmates in the regular classroom, but Facebook Group provided me to do all that I missed in the regular classroom". Most of the students are happy to participate in learning through the Facebook group as this provides an alternative means to manage learning in case students are not able to attend and enjoy regular face-to-face classrooms.

Figure 4. An example of self-reported grades in a quiz.

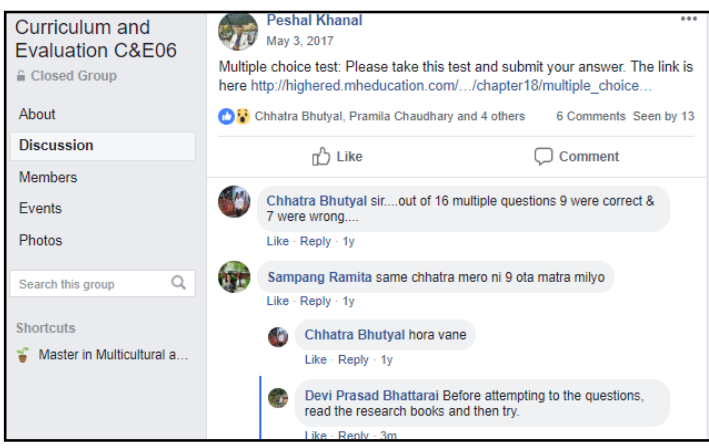

Problems and limitations - Despite several benefits of using the Facebook group for learning, students perceived some difficulties that hinder them from using the Facebook group effectively for academic purposes. For some students, using technology is a burden and for others, there is a sense of fear of peer criticism for poor responses on the Facebook posting. One of the participants in the FGD shared, "I am a slow learner of using technology. So, I am always afraid of being much expressive on the Facebook group. I afraid if I am doing the right thing". The fear is much strong for the students who are not confident in using all the features available for Facebook. Indicating the fear of peer criticism, a student shared, "I am always worried about my posting, and especially my poor English language. If I cannot write a sentence properly or write ideas clearly, I could be criticized. So I don't write much in the group”.

For some students, the Facebook group is problematic when there are diverse opinions on some contents and when the timely availability of teachers is difficult to provide a conclusive remark. A student shared "Teacher is not available in our every discussion and sometimes we remain inconclusive in the absence of the teacher." Mayende et al. (2014) also contend that being a teacher in class is more important, practical and effective for learning because it is hard to explain complex concepts using the Facebook applications. Some difficult and complex contents are difficult to teach using such a virtual forum.

Students' views on using the Facebook group also point to the hazards including headache, dizziness, or addiction. A student asserted, "although the Facebook group has several academic benefits; its frequent use made me feel several problems such as blurred vision, headache and reading anxiety." This indicates that relying solely on such technological applications results in health issues such as headaches, problems with eye vision, and other socio-physiological disorders. Further, the risk of social security and the privacy of the students and teachers is another concern. A student, in this regard, argued, "We use Facebook group informally and use language in our own styles and tones. We sometimes fear that if our conversation becomes a public concern and criticism". The common concern is about the confidentiality and privacy of the information, communication, and interaction between teachers and students. 
An uncommon experience is that mixing academic and entertaining purposes of Facebook sometimes problematic. A participant revealed, "Switching between learning and entertainment application made me problematic. I could not stay with on application ". This reflects why the Facebook group is stressful to the learners if they use Facebook for entertaining and networking purposes rather than academic ones. Meishar-Tal et al. (2012) got a similar response from the students that the multiple uses of Facebook and the need for continually monitoring its posting and message are always problematic. While posts are coming up regularly, there is a chance that students feel bored and skip some of the important comments and postings related to learning.

\section{Conclusion}

Facebook group can facilitate students' learning as an informal forum to continue dialogue and discussion on any learning content beyond the face-to-face classroom. In addition, this forum can be used as a forum for peer networking, feedback and assessment. However, many factors such as teacher's skills and attitudes towards technological applications, students' access to the Internet and IT devices, and students' skills and motivation in ICT-based are crucial for the effective application of the Facebook group for students' learning. As we could not deny the growing application of social media such as Facebook, its learning application should be enhanced. And, for this, we may need to ensure a supportive mechanism in educational institutions, including resources and training, for both teachers and students. There is a growing realization that Facebook is not only meant for entertaining and networking tools but also a multi-purpose virtual forum. Among its several uses teachers and students can utilize it as a means for maximizing the opportunity for students' learning. As this study suggests, because of the nature of the Facebook group as a flexible, informal and interactive tool, it can enhance opportunities for engaged learning.

From the above discussions and conclusion, a few implications can be drawn for teachers and students. First, teachers can use the Facebook group as an informal learning platform and provide students with the opportunity to engage in the interaction among themselves as well as with the teacher. As social media has become popular for informal communication and platform in higher education that contributes to the increased teacher-student and student-student interaction, improved performance, the convenience of learning and higher engagement (Chugh \& Ruhi, 2018), teachers can use the Facebook group for diversified learning opportunities. Second, the use of a Facebook group can be extended to all departments and subjects in order to diversify and maximize the learning opportunity of students. To do so, the professional development course should incorporate the knowledge and skills teachers require to use social media such as Facebook in various ways. Third, as Facebook has been used as an effective platform for communication and collaboration with students, this can be used as an alternative of the Learning Management System (LMS) particularly where the ICT infrastructure is relatively poor. Although the use of Facebook as an alternative to LMS is still under-researched (Niu, 2017), this can be a beginning step of introducing ICT as a supplementary management system of learning in the resource-constrained world in particular (Pimmer et al. 2012). Fourth, as Facebook can be used as a major curriculum resource that can be integrated into the pedagogical component of the curriculum in order to foster student-centered learning (Leier \& Cunningham, 2016), this platform can bridge the gap between the teachers and students. As many students are shy and reluctant to engage in face-to-face dialogue, communication and collaboration with the teacher (Wongsa \& Son, 2020), Facebook can remove this artificial barrier that has been hindering many students from working actively with their teachers. Fifth, there is a need of preparing all teachers to use social media in teaching by some upskilling programs, both formal or informal (Bissessar, 2014). Therefore, the teachers' professional development programs, both pre-service and in-service, should incorporate and embrace multiple approaches to students' learning, including the use of the Facebook group in teaching and learning. Finally, there is a need for encouraging students to use Facebook for academic purposes and motive them to engage in the subject- or program-specific Facebook group that provides a forum where students can network and learn from each other. 


\section{References}

Acharya, S. (2016, February). Internet usage of teenagers in Nepal for educational purposes: An analysis of Internet usage behavior of 15-17-year-old students at selected schools in Kathmandu [An unpublished research report].

Al-Dheleai, Y. M., \& Tasir, Z. (2017). Using Facebook for the purpose of students' interaction and its correlation with students' academic performance. The Turkish Online Journal of Educational Technology, 16(4), 171-178.

Bahati, B. (2015). Extending students' discussion beyond lecture room walls via Facebook. Journal of Education and Practice, 6(15), 160-171.

Bissessar, C. S. (2014). Facebook as an informal teacher professional development tool. Australian Journal of Teacher Education, 39(2). https://doi.org/10.14221/ajte.2014v39n2.9

Chugh, R., \& Ruhi, U. (2018). Social media in higher education: A literature review of Facebook. Education and Information Technologies, 23, 605-616. https://doi.org/10.1007/s10639-017-9621-2

Dulal, R. (2014). Nepal Facebook statistics. http://rdulal.blogspot.com.nepal-Facebookstatistics.html

Dunn, L. (2013, April 9). Teaching in higher education: Can social media enhance the learning experience? [Conference Proceedings]. 6th Annual University of Glasgow Learning and Teaching Conference. Glasgow, UK. http://eprints.gla.ac.uk/78491/1/78491.pdf

Gyambrah, M. K. (2007). E-learning technology and its application in higher education: A descriptive comparison of Germany, United Kingdom and United States [Doctoral Dissertation, University of Munich]. LMU München Repository. https://edoc.ub.uni-muenchen.de/7358/

Jha, R. K.,Sha, D. K., Basnet, S., Poudel, K. R., Sah, P., Sah, A. K., \& Adhikari, K. (2016, August 2). Facebook use and its effects on the life of health science students in a private medical college of Nepal. BMC Research Note, 9, 378. https://doi.org/10.1186/s13104-016-2186-0

Joshi, R. (2020, November). Facebook user in Nepal. https://roshanjoshi.com.np/web/facebook-users-in-nepal/

Leier, V., \& Cunningham, U. (2016). 'Just Facebook me': A study on the integration of Facebook into a German language curriculum. In S. Papadima-Sophocleous, L. Bradley, \& S. Thouësny (Eds.), CALL communities and culture: Short papers from EUROCALL 2016 (pp. 260-264). https://doi.org/10.14705/rpnet.2016.eurocall2016.572

Mayende, G., Muyinda, P. B., Isabwe, G. M. N., Walimbwa, M., \& Siminyu, S. N. (2014, July 15-18). Facebook mediated interaction and learning in distance learning at Makerere University [Conference Presentation]. 8th International Conference on e-Learning, Lisbon, Portugal. https://www.learntechlib.org/p/157776/

Meishar-Tal, H., Kurtz, G., \& Pieterse, E (2012). Facebook groups as LMS: A case study. The International Review of Research in Open and Distance Learning, 1394, 33-48. https://doi.org/10.19173/irrodl.v13i4.1294

Niu, L. (2017). Using Facebook for academic purposes: Current literature and directions for future research. Journal of Educational Computing Research, 56(8), 1384-1406. https://doi.org/10.1177/0735633117745161

Pimmer, C., Linxen, S., \& Gröhbiel, U. (2012). Facebook as a learning tool? A case study on the appropriation of social network sites from mobile phones in developing countries. The British Journal of Educational Technology, 43(5), 726-738. https://doi.org/10.1111/j.1467-8535.2012.01351.x

Rana, K. B. M. (2013). Is Facebook a supportive social networking website in school life? A case of grade $-X$ students in Kathmandu. Rural Aurora, 2(1), 1-7.

Roblyer, M. D., Mc Danniel, M., Webb, M., Herman, J., \& Witty, J. V. (2010). Findings on Facebook in higher education: A comparison of college faculty and student use and perceptions of social networking sites. Internet and Higher Education, 13, 134-140. https://doi.org/10.1016/j.iheduc.2010.03.002

Wessels, C. J. J., \& Diale, B. M. (2017). Facebook as an instrument to enhance the career construction journeys of adolescent learners. South African Journal of Education, 37(4), 1-12. https://doi.org/10.15700/saje.v37n4a1470 
Khanal, P., \& Bhattarai, D. P.

Wongsa, M., \& Son, J. (2020) Enhancing Thai secondary school students' English speaking skills, attitudes and motivation with drama-based activities and Facebook. Innovation in Language Learning and Teaching. https://doi.org/10.1080/17501229.2020.1853134

44 Consortia Academia Publishing (A partner of Network of Professional Researchers and Educators) 